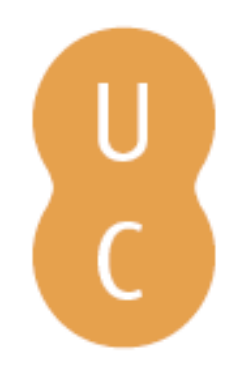

\title{
nombalina
}

\section{Pedro Nunes e a carta de marear}

Autor(es): $\quad$ Gaspar, Joaquim Alves

Publicado por: Imprensa da Universidade de Coimbra

URL

persistente: $\quad$ URI:http://hdl.handle.net/10316.2/38439

DOI: $\quad$ DOI:http://dx.doi.org/10.14195/978-989-26-0764-1

Accessed : $\quad$ 26-Apr-2023 11:04:53

A navegação consulta e descarregamento dos títulos inseridos nas Bibliotecas Digitais UC Digitalis, UC Pombalina e UC Impactum, pressupõem a aceitação plena e sem reservas dos Termos e Condições de Uso destas Bibliotecas Digitais, disponíveis em https://digitalis.uc.pt/pt-pt/termos.

Conforme exposto nos referidos Termos e Condições de Uso, o descarregamento de títulos de acesso restrito requer uma licença válida de autorização devendo o utilizador aceder ao(s) documento(s) a partir de um endereço de IP da instituição detentora da supramencionada licença.

Ao utilizador é apenas permitido o descarregamento para uso pessoal, pelo que o emprego do(s) título(s) descarregado(s) para outro fim, designadamente comercial, carece de autorização do respetivo autor ou editor da obra.

Na medida em que todas as obras da UC Digitalis se encontram protegidas pelo Código do Direito de Autor e Direitos Conexos e demais legislação aplicável, toda a cópia, parcial ou total, deste documento, nos casos em que é legalmente admitida, deverá conter ou fazer-se acompanhar por este aviso. 
Centro Interuniversitário de História das Ciências e da Tecnologia, Faculdade de Ciências, Universidade de Lisboa, Lisboa

alvesgaspar@netcabo.pt

Pedro Nunes e a Carta de Marear

Joaquim Alves Gaspar

Contrariando uma visão romântica e nacionalista do início do século passado, segundo a qual Pedro Nunes terá estado directamente envolvido no desenvolvimento e aplicação da ciência náutica às missões de exploração do século XVI, sabemos hoje que ele foi sobretudo um matemático teórico, e que a sua relação com as matérias práticas da cartografia e arte de navegar nunca foi muito estreita. Pelo contrário, os comentários que deixou escritos sobre a geometria da carta de marear sugerem algum desprendimento relativamente ao seu uso no mar e, em certos casos, uma estranha ignorância sobre os pormenores da sua construção. Um exemplo significativo, do Tratado em defensam da carta de marear (1537), é a interpretação de Nunes sobre a forma como o Mediterrâneo é representado nas cartas da época, sem ter em conta as latitudes dos lugares, onde o matemático parece não se aperceber da influência da declinação magnética. Um outro exemplo bem conhecido do mesmo tratado é a sugestão em substituir as cartas náuticas do seu tempo, construídas a partir de rumos magnéticos e latitudes observadas, por cartas rectangulares, baseadas nas latitudes e longitudes dos lugares, parecendo ignorar a impossibilidade prática de determinar a longitude com exactidão e o efeito da declinação magnética na navegação. Nesta comunicação, os comentários e propostas de Pedro Nunes sobre a geometria das cartas de marear são analisados, à luz do que se conhece sobre os métodos de navegação e cartografia da época.

\section{INTRODUÇÃO}

O papel de Pedro Nunes no desenvolvimento da técnica e ciência náuticas do Renascimento não está isento de polémica. À visão ingénua e nacionalista de alguns autores, segundo os quais o matemático terá tido um papel preponderante na resolução dos problemas da navegação e cartografia do seu tempo, contrapóe-se a interpretação de outros, que entendem que o seu contributo directo nessas matérias terá sido pouco relevante, senão mesmo prejudicial. Em suporte da primeira interpretação são normalmente referidos os tratados que dedicou à discussão de certos problemas de navegação e à análise da geometria da carta de marear, supostamente redigidos como textos didácticos, bem como a concepção de novos instrumentos 
náuticos ${ }^{1}$. Para corroborar a visão alternativa invocam-se as difíceis relações que o matemático terá tido com os homens do mar, os erros que cometeu em algumas indicações que lhes forneceu e a impraticabilidade de certas técnicas e instrumentos que preconizou ${ }^{2}$. A crítica implícita nesta visão não parece despropositada à luz do cargo de cosmógrafo-mor exercido por Pedro Nunes a partir de $1547^{3}$.

Contudo, nenhuma destas interpretaçôes caracteriza com justeza o seu real contributo. Reconhecemos hoje que Pedro Nunes era, sobretudo, um matemático teórico cuja principal preocupação, expressa de forma enfática ao longo da sua obra, foi a aplicação da ciência matemática à arte de navegar. Neste sentido, a sua influência no meio científico europeu foi marcante e duradoura, e a sua contribuição para o desenvolvimento da ciência náutica, tal como hoje a conhecemos, foi relevante e profunda. Por outro lado, e embora parecendo genuinamente preocupado com os problemas concretos que afligiam a navegação e a cartografia da época, em particular com as limitaçōes da carta de marear, Pedro Nunes nunca apresentou soluçôes viáveis para a sua resolução. Pelo contrário, a sua aproximação a essas matérias foi sempre formal e abstracta, solidamente apoiada nos princípios geométricos estabelecidos pelos mestres do passado (sobretudo Ptolomeu), mas por vezes desligada de pormenores práticos essenciais. Tal é o caso da proposta que apresentou no Tratado em defensam da carta de marear, de 1537, em que preconizou a substituição do modelo cartográfico da época pela projecção de Marino de Tiro, ignorando o facto de tal solução ser incompatível com os métodos de navegação então praticados.

O objectivo deste artigo é analisar alguns comentários e propostas apresentados por Pedro Nunes sobre a geometria da carta de marear, à luz do que hoje se conhece sobre os métodos de navegação e cartografia do século XVI. São analisados dois textos: o Tratado em defensam da carta de marear, publicado em 1537, em Lisboa; e, de forma mais expedita, o capítulo 1 do De arte atque ratione nauigandi, publicado primeiramente em Basileia, em 1566, e depois em Lisboa, em 1573.

\footnotetext{
${ }^{1}$ Exemplos significativos desta visão encontram-se em VENTURA (1985), onde se refere Pedro Nunes como 'o pedagogo, o didacta em corpo inteiro - claro, preciso, conciso, acessível' (p. 45), sabendo 'colocar-se entre a posição ex-cathedra e a da homem prático, incorporando a sua experiência e a sua pedagogia ao serviço da aprendizagem e do ensino' (p. 25).

${ }^{2}$ A este respeito, escreve ALBUQUERQUE (1987, p. 156): '[...] talvez tenhamos de rever ideias feitas sobre a presumível benéfica assistência que Nunes prestou à marinharia do seu tempo; no final da sua vida, o almirante Teixeira da Mota [...] disse-nos estar persuadido de que ela fora prejudicial para o desenvolvimento da marinharia portuguesa; não nos atrevemos a ir tão longe, mas estamos em crer que o grande matemático, com as suas observaçōes teóricas, em nada contribuiu para que ela se aperfeiçoasse’.

${ }^{3} \mathrm{O}$ mais antigo regimento do cosmógrafo-mor que chegou aos nossos dias data de 1592 e foi promulgado por Filipe I de Portugal, o qual refere a necessidade de reformar a versão de 1559, do tempo de D. Sebastião. São referidas explicitamente, no regimento de 1592, as seguintes atribuições: examinar todos quantos pretendem vir a fazer cartas de marear e instrumentos náuticos; verificar a correcção de tais cartas e instrumentos; leccionar uma aula de matemática para pilotos, sotapilotos, mestres, contramestres e guardiães, e ainda gente nobre que quisesse assistir; e certificar a sua capacidade através de um exame obrigatório. Não chegou até nós o regimento de 1559, mas presume-se que algumas das suas normas são comuns e sabe-se que Pedro Nunes realizou alguns exames a cartógrafos e construtores de instrumentos náuticos (MOTA, 1969).
} 


\section{O Tratado em defensam da carta de marear}

O Tratado em defensam da carta de marear 4 é uma das duas obras dedicadas à ciência náutica incluídas no Tratado da Esfera, publicado em Lisboa, em 1537. A outra é o Tratado sobre certas dúvidas da navegação, na qual Pedro Nunes estabelece pela primeira vez a distinção entre o arco de círculo máximo e a linha de rumo. Do primeiro tratado, de mais de 50 páginas, somente se discute aqui a parte inicial, dedicada à carta de marear (NUNES 2002, pp. 120-41). Trata-se de um texto longo e complexo, por vezes obscuro ou contraditório, onde a geometria das cartas náuticas utilizadas no início do século XVI é analisada à luz da Matemática, tendo em conta os princípios estabelecidos pelos mestres do passado, em particular por Ptolomeu. De acordo com as palavras do autor, o objectivo da obra é "desculpar a carta das culpas e erros: de que todos geralmente a acusam: e nam as ygnorancias: perfias: e contumacias dos mareantes" (ibidem, 2002, p. 127). Esta mesma ideia é reforçada algumas páginas adiante, quando Nunes afirma que "em tudo isto eu nam digo mal da carta mas aqueyxome de ser mal entendida: sendo ella ho melhor estromento que se podera achar: para a nauegaçam: e descubrimento de terras e a nossa arte de nauegar a mais fundada em sciencias mathematicas [...]" (ibidem, p. 137). Duas ideias-chave parecem conformar o raciocínio de Pedro Nunes, pelo menos na primeira parte do tratado: a de que a carta de marear é a melhor solução possível para apoiar as navegaçōes; e a de que os pilotos são injustos e ignorantes nas críticas que lhe fazem. É interessante verificar como a arte de navegar utilizada pelos portugueses é referida por Nunes com evidente deferência e apresentada como tendo tido origem num passado mais ou menos remoto, quando mestres desconhecidos a terão desenvolvido, com base nas ciências matemáticas. Esta postura indicia, a meu ver, que o matemático não se encontrava ainda na posse de todos os elementos necessários a uma visão esclarecida do problema. Como se verá, a sua opinião sobre esta e outras matérias irá evoluindo ao longo do tratado, acabando mesmo por produzir uma solução alternativa ao modelo cartográfico em uso.

O tratado de Pedro Nunes foi frequentemente invocado como confirmação de que o modelo cartográfico desenvolvido e utilizado pelos portugueses durante o período dos descobrimentos foi a projecção cilíndrica equidistante centrada no Equador, a chamada 'carta quadrada'. Penso ter já mostrado com clareza, em anteriores trabalhos, que esta ideia é um mito e que a sua origem se situa numa interpretação incorrecta do texto 5 . A respeito da carta de marear, Nunes começa por afirmar nas primeiras páginas do tratado (NUNES 2002, p. 121):

"E assim como o caminho que fazemos: faz cô nouos meridianos igual angulo ao que partimos: assim mesmo na carta que representa ho uniuerso: faz sempre a mesma rota com os meridianos angulos iguaes: pollos ditos meridianos serem linhas dereitas e equidistantes: que com a

${ }^{4} \mathrm{O}$ título completo é: Tratado que ho doutor Pero nunez Cosmograho del Rey nosso senhor fez em defensam da carta de marear: cố o regimento da altura. Dirigido ao muyto escrarecido: e muyto excelente Principe ho Iffante dom Luys. No presente trabalho foi utilizada a edição da Academia das Ciência e Fundação Calouste Gulbenkian (NUNES 2002, pp. 120 e seguintes).

${ }^{5}$ Ver GASPAR 2007; 2010, pp. 26-34. 
terceyra linha: que he a per que se faz o caminho: causam de dentro e de fora angulos yguaes. E esta he a razam porque foy necessario: serem os rumos de norte sul: e quaes quer outros de hum mesmo nome: linhas dereitas equidistantes."

Por enquanto, Nunes limita-se a afirmar que o caminho dos navios no mar, ao longo das linhas de rumo, é representado por segmentos de recta correctamente orientados em relação aos meridianos, os quais são, por sua vez, representados por linhas paralelas e equidistantes. De facto, esta propriedade estava implícita na forma como as cartas eram utilizadas pelos pilotos e nas teias de linhas de rumo que continham. Mas a realidade era bem diferente, uma vez que o modo como tais representaçôes eram construídas, com base em direcçôes magnéticas e utilizando uma escala constante, produzia uma geometria distinta ${ }^{6}$. Como se sabe, tal requisito só viria a ser satisfeito com a projecção de Mercator, apresentada em 1569, na qual a escala ao longo dos meridianos cresce continuamente com a latitude, de modo a ser sempre igual à escala ao longo dos paralelos. Escreve logo a seguir Pedro Nunes (ibidem, pp. 121-2):

"Nem se pode fazer de linhas curuas: nenhũ planisferio que tanto conforme seja ao nosso modo de nauegar como he a carta. A qual posto que faça todollos parallelos iguaes a equinocial: e os polos que sam pontos linhas dereitas [...] Porque se bem olharmos: que releua a quem nauega: pera saber o que andou: ou onde esta: que hũa ilha ou terra firme este pintada na carta: mais largado que he: se os graos forem tantos quantos ham de ser de leste a oeste: porque a mim que faço a conta me fica resguardado: saber que estes graos sam na verdade menores do que a carta por ser quadrada amostra: e ver quanto menos leguas contem: e isto per tauoas de numeros ou estromento: como he o quadrante que pera isto costumo fazer: de sorte que quero concluyr: que mais proueito temos da carta: por serem os rumos linhas dereitas equidistantes: que per juyzo porque sendo assi fique quadrada”.

Este excerto não deixa quaisquer dúvidas sobre o tipo de projecção a que Pedro Nunes se refere: a projecção cilíndrica equidistante centrada no Equador, em que meridianos e paralelos formam uma malha quadrada. O matemático vai mesmo ao pormenor de esclarecer que as distâncias ao longo dos paralelos se encontram exageradas e devem ser corrigidas, por tabela ou instrumento, por quem pretenda conhecer os valores correctos. Contudo, é um facto conhecido que as propriedades referidas nos dois textos são incompatíveis entre si, isto é, não é possível numa projecção cilíndrica representar-se as linhas de rumo por segmentos de recta, mantendo constante a escala ao longo dos meridianos. Por outro lado, a forma como as cartas náuticas eram construídas na época, utilizando uma escala constante, produzia uma geometria claramente distinta da projecção cilíndrica equidistante. Tal construção nunca poderia representar os meridianos como segmentos rectilíneos e equidistantes, uma vez que a sua convergência à superfície da Terra seria sempre reflectida na geometria da carta, conclusão que o próprio matemático irá tirar mais adiante.

${ }^{6}$ Para uma introdução sobre os métodos utilizados na construção das cartas durante a Idade Média e Renascimento, ver GASPAR 2010, pp. 21-33. 
É estranho que Pedro Nunes tenha feito tais afirmações no início do seu tratado. Ou ele desconhecia a forma como as cartas de marear eram construídas, o que parece improvável face ao seu estatuto de cosmógrafo, ou estava convicto de que o método utilizado produzia, pelo menos de forma aproximada, uma malha quadrada de meridianos e paralelos. Esta interpretação parece encontrar eco um pouco mais adiante, quando o cosmógrafo se refere ao método sugerido por Ptolomeu para representar os lugares (ibidem, p. 123):

"[...] e per fim disto diz [Ptolomeu] que o milhor modo que se pode ter: he que se faça fundamento: nos lugares cujas longuras e alturas per estromentos forem sabidos: e dahi en diante: per respeito destes se assentem os outros: de que nam ouuer tanta certeza: e ysto porem de sorte: que as rotas fiquem aquellas que na verdade sam."

Isto é, Pedro Nunes parece aceitar que é possível representar correctamente na carta tanto as latitudes e longitudes dos lugares como os rumos e distâncias (rotas) entre eles ${ }^{7}$. Pegando num exemplo de Ptolomeu sobre a posição das cidades de Corura e Parura, Nunes inicia então uma longa discussão sobre a forma que ele utilizou para transferir as distâncias observadas à superfície da Terra para o plano da carta. Acaba por concluir que, embora a técnica do alexandrino (cheo de todas as sciencias mathematicas) seja idêntica à dos cartógrafos portugueses, as posiçôes dos lugares registadas por Ptolomeu na sua Geografia estão eivadas de grandes erros (ibidem, pp. 123-27). Mais adiante, irá aprofundar a sua análise e sugerir que as correcçôes feitas por Ptolomeu tinham provavelmente a ver com a diferenças existentes entre as distâncias medidas sobre linhas de rumo e círculos máximos (ibidem, pp. 127-29), aproveitando para invectivar os pilotos que marcam em linha recta as rotas que efectuaram com vários rodeios. A propósito dessa questão, e referindo-se ao modo como devem ser representadas as rotas efectuadas ao longo dos paralelos, escreve Nunes (ibidem, p. 130):

"E assi digo que o modo que se deue ter pera situar algua ilha que se achasse indo a leste ou oeste de terra firme ou lugar conhecido: ha de ser per legoas que se tomaram có o compaso: contando do logar donde foy a partida: e nam por graos: posto que se achasse per via de eclipses [isto é, por graus de longitude]: porque ainda entam he meu parecer poys a carta faz todolos graos yguaes: que conuertamos a deferença das oras em graos: e os graos em legoas: segundo a proporção que teuerem aos graos grandes: e pello numero das legoas se assente na carta: na qual nam he necessario nem somente nomear graos: e desta sorte ficara a dita ilha bem situada."

É evidente a evolução do seu pensamento nesta matéria. A ideia herdada de Ptolomeu, de que os lugares sobre um mesmo paralelo se devem situar de acordo com as suas diferenças de longitude, deu lugar ao modelo utilizado nas cartas da época, em que se representavam esses mesmos lugares de acordo com as distâncias entre eles.

\footnotetext{
${ }^{7}$ MATOS (2002, pp. 43-5) manifesta alguma perplexidade a respeito deste texto, quando o confronta com o método minuciosamente descrito por Francisco da Costa no seu Tratado de Hidrografia, publicado no final do século XVI (ALBUQUERQUE 1969, pp. 107-13). Ao contrário de Francisco da Costa, Nunes parece não fazer a distinção entre as cartas construídas pelos geógrafos, com base nas latitudes e longitudes dos lugares, com as construídas pelos hidrógrafos, com base em latitudes, rumos e distâncias.
} 
A seguir, irá discutir longamente esta sua conclusão através da análise de dois exemplos concretos. Mas Pedro Nunes não se irá limitar à discussão sobre as posiçôes relativas na direcção este-oeste. Tendo já aceitado que as distâncias ao longo dos paralelos devem ser respeitadas, facilmente se apercebe que esta propriedade se irá reflectir na orientação dos meridianos, os quais não poderão, afinal, ser representados por segmentos rectilíneos e paralelos entre si. A propósito da análise que efectuou sobre as posiçôes relativas do Cabo Carvoeiro e da Ilha Terceira na carta de marear (Figura 1, esquerda), conclui Pedro Nunes (ibidem, p. 132):

"E as razões que acima fiz contra isto: concruem a verdade .s. que a dita ilha [Terceira]: e o ponto .b. que tomey na linha [equinocial] e dista de .a. per .262. legoas nam estam norte sul: porque o seu meridiano corta a equinocial mais ao loeste de .b. quatro graos e meo: que sam perto de oytenta leguas: e por tanto quem partisse da dita ilha e fosse buscar o pónto .b. da equinocial não o acharia ao sul: como na na carta parece: mas quasi a mea quarta mais do sueste."
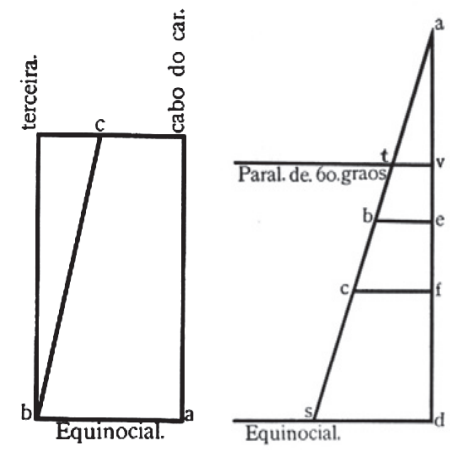

Figura 1 - As figuras que ilustram o raciocínio de Pedro Nunes quando mostra que a linha vertical que liga a Terceira ao Equador, na carta de marear, não pode ser um meridiano (esquerda) (NUNES 2002, p. 131) e quando demonstra que o segmento as, que contém dois lugares situados no mesmo meridiano ( $b$ e $c$ ), não pode ser um meridiano (direita) (ibidem, p. 140). A linha $a d$, na

figura da direita, representa o meridiano que passa pela costa oeste de Portugal.

Este é um resultado de grande relevância na interpretação da geometria da carta, em que a ideia da malha quadrada é finalmente abandonada e se reconhece o efeito da convergência dos meridianos. Mas Pedro Nunes não tarda a generalizar, desta vez de forma enfática, o resultado do seu raciocínio (ibidem, pp. 132, 33):

"E os mareantes aporfiam assi ho que nam sabem como o que sabem. Porque aquelles lugares estam em verdadeyras rotas: que per ellas se acharam: mas nam ja as que se seguem: da verdadeira situaçam doutros lugares. [...] Enganados andam logo os pilotos: e os que presumem que ho sam: se nam sam bõs mathematicos: em cuydarem que nam há cousa mais certa na carta: que o que nella esta norte sul. E daqui vem que muitas vezes vam buscar hũa terra: que na carta esta norte sul: ou per outra rota: com ho lugar dôde he a partida: e porque a nam acham: nam sabem dar a isto outro desconto: se nam que ou as águas os abaterã: ou a agulha lhes nordesteou ou noresteou: mas a verdade era que nam hiam pello verdadeiro caminho $[\ldots]$ " 
Nunes chama a tenção para o facto de a carta não representar correctamente os rumos entre todos os lugares mas somente aqueles que foram observados. Trata-se de um ponto central para a compreensão da geometria da cartografia náutica pré-Mercator, em que as posições dos lugares numa determinada carta são dependentes do conjunto particular de rotas utilizado para os representar ${ }^{8}$. Pedro Nunes não se limita a mostrar que os meridianos na carta de marear não podem ser paralelos entre si e que a direcção norte-sul nela indicada não coincide, em regra, com a direcção dos meridianos. Já perto do final da sua análise (ver secção seguinte), irá demonstrar que estes não são, em geral, representados por segmentos de recta.

\section{A RepresentaÇÃo do Mediterrâneo}

Pedro Nunes dedica algumas páginas do Tratado à discussão do modo como o Mediterrâneo "o Levante" é representado nas cartas de marear. Trata-se de uma das partes mais interessantes da obra, na medida em que as imperfeiçôes que ele detecta suscitam a discussão de questôes de maior generalidade. Escreve Pedro NUNES (2002, p. 134):

"E porque eu trouxe muito tempo pensamento de emendar ho leuante nas cartas: quero dar disto razam. Nam duuido que se algũas terras se podem per nauegaçam verificar no que pertençe a Cosmogr[af]ia: sam as costas de leuante: assi por as nauegaçôes que per elle se fazem: serem mais frequentes que per outras nenhũas partes: como por nam caberem nisso grandes erros: por os mays dias auerem vista de terra: e saberam on de estam [...]"

Nunes começa por afirmar que, uma vez que as navegações no Mediterrâneo são muito frequentes e não cabem nelas grandes erros, se esperaria que as respectivas costas se encontrassem bem representadas nas cartas. Prossegue depois, dando conta da ignorância dos cartógrafos sobre esta matéria e do facto de as partes do Levante serem copiadas de cartas provenientes de Maiorca (ibidem, p. 134):

“[...] e por isto ser assi nam curam os que per elle nauegam de trazerem estrelabios: nem estromentos daltura: porque per rotas e estimaçam do caminho que tem andado: fazem seus pontos [...]. Mas porque per discurso de tempo: as outras costas de ponente e Guine: se assentaram per alturas: quando vieram a continuar o leuante com ponente: ficaram os portos de leuante fora de suas alturas. [...] Esta foy segundo meu parecer a causa dos lugares de leuante terem mudadas as alturas. Nem achey quem me soubesse dar razam disto: nem somente homem que lhe passasse pello pensamento: estar algũa cousa em leuante mal situada e posto que ho preguntey nam me responderam outra cousa: se nã que estas cartas de leuante: de que nestas partes tirauam: vinham de Malhorca: onde ellas antiguamente se faziam [...]”

Nunes explica que, ao contrário do que acontece no Atlântico, as navegações no Mediterrâneo se faziam pelo método do rumo e estima, não havendo lugar a observações

${ }^{8}$ Para uma explicação detalhada sobre a inconsistência geométrica das cartas náuticas desta época ver GASPAR (2010, pp 32-3) e GASPAR (2011, pp 230-32). 
da latitude. E sugere que os erros que detectou nas latitudes dos lugares se devem precisamente ao facto de se misturar representaçôes baseadas em latitudes (as costas do poente e da Guiné) com as baseadas em rumos e distâncias estimadas "o Levante". Escreve logo a seguir, tentando explicar as discrepâncias (ibidem, pp. 134-35):

"[...] e cuydando muitas vezes nysto: assentey que per algum modo dos que agora direy: ficaram estes lugares fora de suas alturas: conuem a saber que per ventura o leuante esta bem situado: mas quando ajuntaram com o ponente pellas portas do estreito [o estreito de Gibraltar]: ficou todo elle mais alto do que auia destar. Ou ouve erro no conformar as milhas com as legoas e graos: de que fora de leuante se vsa [...] podia ser tambem: que as rotas sejam certas: e a cantidade do caminho que per estimaçã determinam seja falso: porque desta sorte as alturas e proporcionalmente as longuras ficam falsas. E o mesmo sera se a cantidade do caminho esta no certo: mas nas rotas ha mudança da verdade $[\ldots] ”$

Nunes enumera aqui as possíveis causas para os erros de latitude que encontrou: uma má conversão, por parte dos cartógrafos, das unidades de distância utilizadas no Mediterrâneo; e erros nas distâncias ou nos rumos registados pelos pilotos. A seguir (ibidem, pp. 135-6) irá mostrar geometricamente de que modo os erros que enumerou afectam as latitudes e longitudes dos lugares. Repare-se como Nunes se situa num plano estritamente teórico, já que nem ele nem nenhum dos cartógrafos ou pilotos que contactou tinham conhecimento de como a representação do Mediterrâneo, copiada de protótipos mais antigos, tinha sido adaptada às cartas portuguesas de latitude. Um pouco mais adiante, irá comparar a extensão longitudinal do Mediterrâneo nas cartas do seu tempo com a registada na Geografia de Ptolomeu (ibidem, p. 136):

"As cartas parece que sam nisto diferentes das tauoas de Ptolomeu: porque elle póe sesenta e tres graos e meo do meridiano das canarias ao fim de Africa em leuante onde esta pelusio [...] mas nas cartas nam ha mais que cinquemta e dous graos: e assi por isto: como por esta costa de leuante: no fim della estar nas cartas muyto alta [...] fica este estreyto de terra: a que chamamos em cosmografia Ismo: descompassadamente grande [...] Mas se bem oulharmos isto: nam auera razam de nos espantarmos: porque estes cincoenta e dous graos que a carta mostra sam graos grandes em que ha .900. e tantas legoas e per legoas ou milhas se nauega em leuante: e se deue nauegar em toda parte e nam per graos como acima disse."

Nunes conclui que, enquanto o Levante se encontra representado nas cartas de acordo com a sua medida em graus grandes (isto é, de acordo com o seu comprimento), o número de Ptolomeu se refere a graus de longitude. Tal seria aliás, a par com os erros de latitude, uma das razões para o tamanho exagerado do Istmo de Suez. Depois de uma breve discussão, em que invectiva os construtores de globos pelos erros que cometem ao extrair as distâncias leste-oeste das cartas como se de diferenças de longitude se tratassem, Pedro Nunes reafirma a sua confiança na carta de marear (ibidem, p. 137), através do conhecido texto já transcrito atrás: [...] e em tudo isto eu nam digo mal da carta mas aqueyxome de ser mal entendida [...]. Logo a seguir retoma as comparaçốes entre a Geografia de Ptolomeu e as cartas, desta vez a respeito da largura do continente africano (ibidem, pp. 38): 
"Ptolomeu veuia em alexandria [e] trabalhaua por ter verdadeyras enformações. Ao menos de Leuante e das partes mais vezinhas [...]. E porem sem embargo disto achou: per suas enformaçôes do sartão: que ho cabo de Guardafuy: que elle chama aromata: distaua do meridiano de Guardafuy per .83. graos. Este mesmo cabo descobrirão os Portugueses: nam per eclipses como Ptolomeu: nem por terra: nem nauegando per leuante: mas com tamanhos rodeos: como se fazem em tam comprido caminho: como he o da India [...]. Esperava eu que este cabo aromata: nos saysse em muito diferemte longura da que Ptolomeu lhe deu: e lançandolhe o compasso: acho que dista do meridiano das Canarias pelos mesmos oytenta e tres graos. Ora manifesto he: que os portugueses nam lhe foram por esta longura: pera conformar com Ptolomeu [...] quanto mais que andam as nossas cartas tam gizadas: que pera fazer isto era necessario mudar todalas rotas: o que se nam podera sofrer. E pois estas vias sam tam diferentes no modo de descobrir este cabo: e vem ambas nisso a conformar: he bem que cuidemos: que as nauegações de Portugal: sam as mais certas: e milhor fundadas: que nenhũas outras.”

Pedro Nunes espanta-se que a largura do continente africano medida em graus, à latitude do Cabo Guardafui, coincida com a correspondente diferença de longitudes indicada por Ptolomeu. E conclui, acertadamente, que esse valor não deve ter sido copiado da obra do alexandrino. As cartas da época eram construídas com bases em latitudes e rumos entre lugares, e utilizadas de acordo com o mesmo princípio. Desenhá-las de outra forma iria pôr em causa a sua utilidade como instrumento de apoio à navegação (que pera fazer isto era necessario mudar todalas rotas: o que se nam podera sofrer). No entanto, Nunes comete um erro formal na sua apreciação: a extensão de $83^{\circ}$ indicada por Ptolomeu é uma diferença de longitudes e não pode ser comparada directamente com a largura de África medida sobre a carta, a qual é expressa em graus equatoriais (ou graus de latitude, que são idênticos). Se este valor fosse convertido em graus de longitude (à latitude do Cabo Guardafui, cerca de $12^{\circ} \mathrm{N}$ ), o resultado seria cerca de $85^{\circ}$.

Mas a maior falha de Pedro Nunes, na sua discussão sobre a representação do Mediterrâneo e a largura de África nas cartas, é de natureza diferente. Como sabemos hoje, as cartas de marear utilizadas na época eram desenhadas a partir dos rumos indicados pela agulha de marear, não corrigidos da declinação magnética, o que afectava consideravelmente a sua geometria. No caso das cartas-portulano, que eram baseadas em rumos e distâncias estimadas, a distribuição espacial da declinação magnética reflectia-se na orientação dos meridianos e paralelos. Essa é a razão pela qual o eixo do Mediterrâneo nessas cartas aparece rodado no sentido contrário ao dos ponteiros do relógio de um ângulo que é aproximadamente igual ao valor médio da declinação magnética na região, durante a época em que as primeiras cartas foram construídas (século XIII). Nas cartas de latitude, baseadas em rumos e latitudes, a declinação magnética somente afectava a posição longitudinal dos lugares, sendo os paralelos sempre representados por linhas aproximadamente equidistantes e orientadas na direcção este-oeste. Tal como Henrique Leitão notou (NUNES 2008, p. 620) a omissão de Pedro Nunes parece difícil de explicar, tanto mais que o cosmógrafo conhecia bem o fenómeno da declinação magnética.

${ }^{9}$ Este é, contudo, um erro menor, sendo provável que se trate de uma aproximação assumida pelo cosmógrafo, tendo em conta o pequeno valor da latitude. 
A discussão sobre a largura de África nas cartas e na obra de Ptolomeu vai levar em seguida Pedro Nunes a retomar e aprofundar a discussão encetada mais atrás sobre a representação dos meridianos na carta (ibidem, p. 138):

"E porque na carta nam ha outra cousa que emendar: somente nas terras que amostra estarem norte sul: que nom he geralmente verdade: darey modo como se ysto aja de resguardar per esta arte. Buscarey algũa costa na carta: onde quer que seja: que eu sayba certamente: que se corre norte e sul [...] e sera a costa de portugal a qual tomarey per fundamento [...]"

Através de uma longa demonstração, mostrará que os meridianos não só não são geralmente paralelos entre si, mas também que não são representados por segmentos de recta (figura 1, à direita) (ibidem, p. 141):

"E porque de arco a arco he mayor proporção que de sino a sino [...] seguese que antre as distancias dos pontos .c. e .b. ao polo no globo: he mayor proporção que de .a.c. pera .a.b. E por tanto a linha dereita.a.b.c.s. posto que ajunte .b. com .sc. [...] não pode representar meridiano.”

\section{MAS O MELHOR SERIA...}

Logo a seguir, Pedro Nunes remata a sua discussão sobre a geometria da carta de marear com o conhecido texto (NUNES 2002, p. 141):

"Mas o milhor seria pera escusarmos todos estes trabalhos: que fizessemos a carta de muitos quarteyrōes: de bom compaso grande: nos quaes guardemos ha proporção do meridiano ao paralello do meo: como fez Ptolomeu nas tauoas das prouincias: porque assi ficariam todas as longuras alturas e rotas no certo ao menos nam auera erro notauel: e trazer-se a carta em liuro [...] E nos quarteirões em que nam ouuver terra: que passe de dezoyto graos daltura poderemos fazer todolos graos iguais aos do meridiano [...]"

Pedro Nunes sugere a divisão da carta em folhas (muitos quarteyrōes), de escala grande (bom compaso grande), desenhadas na projecção cilíndrica equidistante, ou projecção de Marino de Tiro (como faz Ptolomeu nas tauoas das prouincias), em cada uma das quais se conserve a proporção entre os arcos de meridiano e do paralelo médio (nos quaes guardemos ha proporção do meridiano ao paralello do meo), sendo o respectivo conjunto reunido num atlas (e trazer-se a carta em liuro). Trata-se de um texto surpreendente, à luz do objectivo que foi expresso no início do tratado - desculpar a carta das culpas e erros: de que todos geralmente a acusam - e das palavras do próprio cosmógrafo sobre a adequação da carta às navegaçôes: isto eu nam digo mal da carta mas aqueyxome de ser mal entendida: sendo ella ho melhor estromento que se podera achar: para a nauegaçam: e descubrimento de terras. Referi-me já longamente, noutros trabalhos (GASPAR, 2005, pp. 336-41; 2010, pp. 27-8), às razōes porque considero não ter esta proposta um carácter prático, devendo antes ser considerada como mera hipótese intelectual. Duas causas principais impediam que a sugestão fosse concretizada, de forma satisfatória, na época em que Pedro Nunes a fez: as dificuldades associadas à determinação da longitude dos lugares a representar na carta, 
tarefa necessária à construção do novo modelo ${ }^{10}$; e a necessidade de conhecer o valor da declinação magnética nos locais onde se navegava, a fim de converter todos os rumos indicados pela agulha em rumos verdadeiros (e vice-versa) ${ }^{11}$. Não há provas materiais de que Pedro Nunes, na sua qualidade de cosmógrafo do reino (e, a partir de 1547, de cosmógrafo-mor), tenha tentado concretizar a sua sugestão. O único possível indício é o texto do cartógrafo Lopo Homem, de $c a$. 1560, em que este critica severamente um novo padrão que o cosmógrafo-mor terá mandando fazer, com base em observações de longitude (MATOS, pp. 318-322):

"O doctor Pedro Nuñez mandou fazer um padrão de navegar sobre y per rezão do effeto e aparencias dos euclipses do sol e da lua y se o ofereceo de mostrar al dicho rei de Portugal, por el que do meridiano de Lisboa à Índia era menos distancia e longitud de graos equinociaes do que se mostrava nas cartas de navegar antigas [...] Todas as cartas que por este padrão se fizeram e se fazem em o Armazém, são mui desvairadas de toda a verdade e ciência de navegar, e em todas as armadas que foram á Índia se fizeram e aconteceram muitos maus recados e más viagens em o navegador por elas e se perderam muitas armadas de el-rei, que Deus tem, por serem mui falsas e fora de toda a razão e verdade."

Até que ponto a crítica feroz de Lopo Homem reflecte com exactidão a realidade, designadamente quanto às nefastas consequências do novo padrão? Não sabemos. Teria este novo padrão de Pedro Nunes algo a ver com a sua sugestão de utilizar a projecção de Marino de Tiro? Desconhecemos também. O facto é que tal padrão cartográfico, ou qualquer carta nele baseada, não chegaram aos nossos dias. Existe um atlas náutico anónimo de $c a$. 1537, atribuído por Armando Cortesão e Teixeira da Mota a Gaspar $V_{\text {Viegas }}{ }^{12}$, cujas 14 folhas apresentam uma graduação de longitude. Contudo, tal graduação é obviamente postiça e as escalas são comuns a todas as folhas, o que afasta a hipótese de o atlas se basear no modelo de Pedro Nunes. Repare-se, no texto de Lopo Homem, na expressão 'mui desvairadas de toda a verdade', em que ele se refere provavelmente aos rumos indicados pela carta. De facto, representar os lugares de acordo com as suas longitudes teria como consequência alterar os rumos magnéticos, informação bem mais importante para os pilotos.

Muitos autores discutiram a possibilidade de a sugestão de Pedro Nunes ser uma versão aproximada da projecção de Mercator, tendo a generalidade rejeitado tal hipótese (ver, por exemplo, Pereira da SILVA, 1925, p. 203 e Fontoura da COSTA, 1983, pp 39-40), opinião que partilho. No meu entender, o texto do tratado refere a construção

${ }^{10} \mathrm{Na}$ época de Pedro Nunes as longitudes dos lugares podiam ser determinadas através de vários métodos astronómicos baseados em ocultações de astros (por exemplo, das estrelas pela Lua) ou em eclipses lunares. Contudo, a sua aplicação prática estava limitada aos momentos em que os fenómenos ocorriam, as observações só podiam ser realizadas em terra e a exactidão dos resultados era muito pobre.

${ }^{11} \mathrm{O}$ facto de as novas cartas serem construídas a partir das latitude e longitudes dos lugares não impediria os pilotos de continuarem a utilizar os métodos antigos, baseados em latitudes, rumos e distâncias estimadas, desde que os rumos fossem corrigidos da declinação magnética. Essa correcção era, contudo, dificultada pelo facto de se desconhecer, com a exactidão adequada, a variação espacial da declinação magnética nos locais onde a navegação era praticada. Recorde-se, aliás, como estas mesmas dificuldades viriam a contribuir para a adopção tardia da projecção de Mercator, apresentada em 1569 mas só plenamente aceite pelos pilotos na segunda metade do século XVIII.

${ }^{12}$ CORTESÃO e MOTA, 1987, Vol. I, pp 117-21, Estampas 45 a 57. 
de um atlas náutico com folhas separadas, em que se fazia variar a escala das longitudes de folha para folha, mantendo constante a escala das latitudes (e, em consequência, a escala de léguas da carta). Imaginando que era desenhado um número muito elevado de folhas, e que estas eram dispostas contiguamente, de modo a alinhar os respectivos meridianos centrais, o resultado seria próximo da projecção sinusoidal, ou de Flamsteed, em que a escala linear é conservada ao longo do meridiano central e de todos os paralelos. Uma aproximação da projecção de Mercator só seria obtida se a escala de cada folha fosse aumentada de modo a garantir a continuidade gráfica dos meridianos entre elas, solução que não é aparente no texto de Pedro Nunes. Aliás, a discussão sobre que fatia de glória lhe deve ser atribuída pela invenção da projecção de Mercator parece-me estéril, quando é unicamente baseada naquela proposta. A verdade é que o seu maior contributo para o desenvolvimento da Cartografia foi, em geral, a introdução da matemática no ramo do conhecimento a que hoje chamamos 'ciência náutica' e, em particular, a descoberta e formalização da linha de rumo, ou loxodrómia.

\section{O TRATADO DE 1566}

Em 1566 Pedro Nunes publicou em Basileia o seu mais importante trabalho, com o título genérico Petri Nonii Salaciensis Opera. Devido ao elevado número de erros tipográficos que continha, a obra viria a ser reeditada em Lisboa, em 1573. Nesta nova edição, os textos dedicados à náutica encontram-se reunidos em dois 'livros', sob o título genérico De arte atque ratione nauigandi - 'Sobre a arte e a ciência de navegar'. O Livro I, De duobus problematis circa nauigandi artem é uma tradução revista do Tratado sobre certas duuidas de navegação, de 1537, onde o cosmógrafo responde às dúvidas levantadas por Martim Afonso de Sousa. O Livro II, De regulis et instrumentis, é um longo e minucioso estudo sobre alguns assuntos abordados de forma superficial no Tratado em defensam da carta de marear.

Dos seus 27 capítulos, somente interessa analisar aqui o Capítulo 1, onde a geometria da carta de marear é discutida ${ }^{13}$. Trata-se de uma versão revista e reduzida do texto correspondente de 1537 , onde o autor reafirma os resultados a que tinha então chegado. Nela são eliminadas as referências à teimosia e ignorância dos pilotos, e simplificados alguns dos argumentos e demonstrações. A parte do texto de 1537 onde Nunes afirma que as cartas de marear apresentam uma malha quadrada de meridianos e paralelos é também eliminada. A interpretação do cosmógrafo sobre os erros de longitude na representação do Mediterrâneo não sofre alteração significativa. Contudo, é um pouco mais clara a sua opinião sobre as causas possíveis de tais distorçôes, que ele sugere serem o resultado de erros dos pilotos no registo das direcçôes e distâncias (NUNES 2008, pp. 291-2).

É também mantida, em moldes muito semelhantes, a sugestão feita em 1537 sobre a adopção da projecção de Marino de Tiro, o que indicia que o seu pensamento nesta matéria não evoluiu durante os cerca de 30 anos que medearam entre as duas obras.

${ }^{13}$ Para uma descrição pormenorizada da obra ver as Anotações Gerais de Henrique Leitão em NUNES, 2008 (pp. 517 e seg), especialmente as p. 538-545. 
Se a experiência a que Lopo Homem se refere sobre o novo padrão baseado em longitudes tivesse tido uma relação directa com tal proposta, tal não deixaria de ser referido pelo cosmógrafo no texto de 1566 . Duas pequenas diferenças em relação à versão de 1537 são de referir, embora não as considere uma evolução relevante no pensamento do autor (Ibidem, p. 299): a ideia de que, nas novas cartas rectangulares, a longitude da totalidade do orbe deve ser representada; e a recomendação de que poucos ou nenhuns dos lugares representados na carta de marear comum devem ser transpostos para o novo modelo, devido à incerteza das suas longitudes. Relativamente ao primeiro ponto, é difícil de imaginar um atlas do mundo composto de muitas folhas, cada uma delas contendo toda a circunferência do globo. No caso das duas folhas representado o intervalo de latitudes $0^{\circ}-18^{\circ} \mathrm{N}$ and $S$ (como recomendado em 1537), a razão entre as correspondentes altura e comprimento seria " $18: 360=1: 20$ ", o que é obviamente incompatível com qualquer uso prático ${ }^{14}$. Contudo, e uma vez que Pedro Nunes não se refere explicitamente, no texto de 1566, a um atlas composto de várias folhas, as suas palavras poderão eventualmente ser interpretadas como uma sugestão de construir uma única folha representado o Mundo ${ }^{15}$. À luz desta interpretação, somente um pequeno passo separa as geometrias do modelo de Nunes e da projecção de Mercator, o qual consistiria em ajustar as escalas das várias partes de modo a garantir a continuidade gráfica dos meridianos. No entanto, tal passo nunca foi dado de forma explícita e provavelmente nunca saberemos se tal ideia passou pela sua cabeça ou não (figura 2).
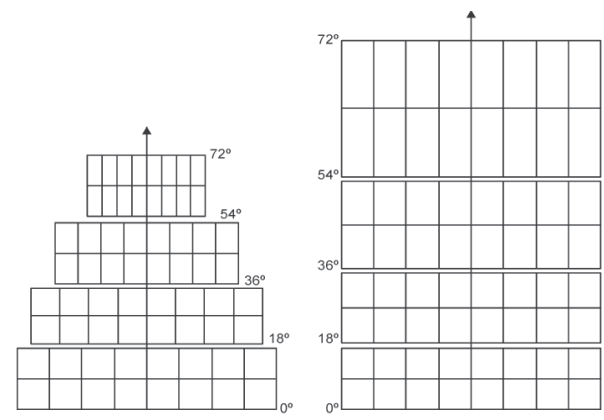

Figura 2 - O novo modelo de carta de marear proposto por Pedro Nunes. À esquerda, a versão implícita na proposta de 1537. À direita, uma possível interpretação da versão de 1566. Ao contrário do que é recomendado por Nunes, somente um terço da circunferência equatorial da terra é representado (adaptado de GASPAR, 2005, p. 338).

\section{Considerações Finais}

Foram comentados neste artigo dois textos de Pedro Nunes, onde ele analisa a geometria da carta de marear: o Tratado em defensam da carta de marear, de 1537, e, de

\footnotetext{
${ }^{14}$ Por exemplo, a um comprimento de $100 \mathrm{~cm}$ corresponderia uma altura de $5 \mathrm{~cm}$.

${ }^{15}$ Devo esta interpretação a João Filipe Queiró, que a exprimiu na comunicação que efectuou no $24^{\circ}$. Seminário Nacional de História da Matemática, realizado em 17 e 18 de Junho de 2011, na Escola Naval.
} 
forma expedita, o Capítulo 1 do De regulis et instrumentis, de 1566. Duas conclusões de ordem geral podem ser retiradas da leitura destes textos: a de que a sua abordagem é essencialmente teórica; e a de que nenhum deles tem um carácter didáctico. No Tratado de 1537, Nunes parece situar-se em dois registos paralelos, por vezes contraditórios: a do reverencial admirador da arte náutica dos antigos, cujas realizaçôes ele defende das críticas e incompreensões dos homens do mar; e a do intelectual que analisa de forma rigorosa o objecto de estudo. No fim, parece prevalecer o segundo registo e Pedro Nunes acaba por reconhecer, embora de forma implícita, que as críticas dos pilotos à carta de marear tinham fundamento.

A aparente ignorância do cosmógrafo sobre a forma como a carta de marear era construída, evidenciada no início do tratado, será progressivamente mitigada ao longo do estudo, através da observação da própria carta e de um processo de dedução intelectual. Nunes acabará por reconhecer que o modelo de Ptolomeu, baseado em latitudes e longitudes, não é adequado às navegaçôes, que a posição relativa dos lugares ao longo dos paralelos deve reflectir a distância entre eles e que as direcções indicadas pela carta não são geralmente correctas. No entanto, não será reconhecida a influência preponderante da declinação magnética na geometria das cartas, que é a razão principal das distorções na representação do Mediterrâneo e da região compreendida entre este e o Cabo Guardafui. A sugestão de Pedro Nunes de substituir o modelo cartográfico em uso pela projecção de Marino de Tiro, sob a forma de um atlas de muitas folhas em que as distorções fossem localmente minimizadas, é teoricamente correcta e um passo importante para a dedução da projecção de Mercator. Contudo, a proposta era irrealizável na prática, já que não era possível determinar a longitude com a exactidão adequada e a navegação se fazia com base em rumos magnéticos. $\mathrm{O}$ facto de o pensamento de Pedro Nunes nesta matéria não ter evoluído ao longo dos cerca de 30 anos que separam a publicações dos dois tratados reforça a ideia de que tal proposta era uma mera hipótese teórica e de que a atenção do cosmógrafo estava voltada para outros assuntos.

Não obstante os erros e omissóes de Pedro Nunes, em grande parte resultantes de uma aproximação essencialmente teórica, o contributo do cosmógrafo para a compreensão da geometria da carta de marear foi original e relevante. Embora a sua qualidade não possa porventura comparar-se à de outras obras do cosmógrafo, designadamente a descrição e formalização da loxodrómia na esfera, os textos aqui analisados devem ser encarados como os primeiros passos de um longo processo de reflexão partilhado por outros sábios europeus (designadamente por Gemma Frisius, Mercator, John Dee e Edward Wright), o qual haveria de levar à construção e formalização da projecção de Mercator.

\section{REFERÊNCIAS:}

ALBUQUERQUE, Luís de - Duas Obras Inéditas do Padre Francisco da Costa. Coimbra: Junta de Investigaçōes do Ultramar, 1969. (Agrupamento de Estudos de Cartografia Antiga; Sep. 52)

ALBUQUERQUE, Luís de - Pedro Nunes e os homens do mar do seu tempo. In A Náutica e a Ciência em Portugal. Lisboa: Gradiva, 1987. p. 145-56.

CORTESÃO, Armando; MOTA, Adelino Teixeira da - Portugaliae Monumenta Cartographica. Lisboa: Imprensa Nacional - Casa da Moeda, 1987. 6 vol. Ed. fac-similada. 


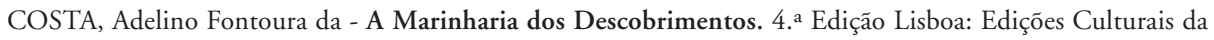
Marinha, 1983. 1. a Edição: Lisboa, Anais do Clube Militar Naval, 1934.

GASPAR, Joaquim Alves - Qual o sistema de projecção das cartas de marear? Anais do Clube Militar Naval. [S.l. : s.n.], Vol. 135 (2005), p. 313-343.

GASPAR, Joaquim Alves - The myth of the square chart. e-Perimetron. [S.1. : s. n.] Vol. 2, n. 2 (2007), p. 66-79.

GASPAR, Joaquim Alves - From the Portolan Chart of the Mediterranean to the Latitude Chart of the Atlantic: Cartometric Analysis and Modeling. Lisboa : ISEGI/Universidade Nova de Lisboa, 2010. Tese de Doutoramento.

GASPAR, Joaquim Alves - Using Empirical Map projections for Modeling Early Nautical Charts. In Anne Ruas Advances in Cartography and GISiences: Selection from ICC 2011, Paris. London [etc.]: Springer, 2011. Vol. 2. p. 227-47.

MATOS, Luís de - Les Portugais en France au XVIème Siècle. Coimbra: Universidade de Coimbra, 1952.

MOTA, Avelino Teixeira da - Os regimentos do cosmógrafo-mor de 1559 e 1592 e as origens do ensino náutico em Portugal. Memórias da Academia das Ciências de Lisboa (Classe de Ciências), Vol. 13 (1969), p. $227-291$.

NUNES, Pedro - Obras : Tratado da Sphera; astronomici Introductorii de Spaera Epitome. Lisboa: Academia das Ciências de Lisboa [etc.], 2008. Vol. 1. 1. a Edição: Lisboa, 1537.

NUNES, Pedro - Obras : De arte Atque Ratione Navigandi. Lisboa : Academia das Ciências de Lisboa [etc.], 2008. Vol. 4. 1. Edição: Lisboa, 1566.

SILVA, Luciano Pereira da - Pedro Nunes espoliado por Alonso de Santa Cruz. Lusitania. Lisboa. Vol. 2, fasc. 8 (1925) 